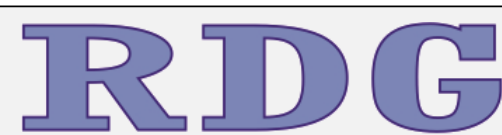

Revista do Departamento de Geografia USP

ISSN 2236-2878
Revista do Departamento de Geografia

Universidade de São Paulo

www.revistas.usp.br/rdg

V.31 (2016)

\title{
ANÁLISE DE ELEMENTOS DO RELEVO ATRAVÉS DO TOPOGRAPHIC POSITION INDEX (TPI) DA BACIA HIDROGRÁFICA DO ARROIO PUITÃ - OESTE DO RIO GRANDE DO SUL/BRASIL
}

\section{ANALYSIS OF RELIEF ELEMENTS THROUGH THE TOPOGRAPHIC POSITION INDEX (TPI) IN THE ARROIO PUITÃ WATERSHED-RIO GRANDE DO SUL/BRAZIL}

\author{
Romario Trentin \\ Universidade Federal de Santa Maria \\ romario.trentin@gmail.com \\ Luis Eduardo de Souza Robaina \\ Universidade Federal de Santa Maria \\ Débora da Silva Baratto \\ Universidade Federal de Santa Maria
}

Recebido (Received): 07/07/2015 Aceito (Accepted): 31/08/2015
DOI: http://dx.doi.org/10.11606/rdg.v31i0.100267

Resumo: O presente trabalho teve como objetivo a determinação de classes do Topographic Position Index (TPI) na bacia hidrográfica do arroio Puitã. O arroio Puitã localiza-se no sul do Brasil, oeste do estado do Rio Grande do Sul. A base altimétrica para a definição do Topographic Position Index, foram os dados de radar do "Shuttle Radar Topography Mission" (SRTM). O TPI é a base do sistema de classificação e, é simplesmente a diferença entre um valor de elevação de células e a altitude média da vizinhança em torno dessas células. Valores positivos significam que a célula é mais elevada do que os seus arredores, enquanto valores negativos significa que é mais baixa. A escala utilizada para a definição das classes de TPI, foi de 10 pixeis, ou seja, foi utilizado um raio de 10 pixeis para a análise da vizinhança que compõem a média de altitude e estabelece o valor de TPI do pixel central. As classes de TPI determinadas foram assim denominadas: vales; áreas planas; encostas suaves; encostas onduladas; encostas íngremes e topo das encostas. A área de encostas suaves predomina na bacia com $38,06 \%$ da área total. As áreas de encostas onduladas e áreas planas são as segunda e terceira, em área, com $27,15 \%$ e $27,11 \%$, respectivamente. A área de topo das encostas é a que ocupa a menor área, com apenas $0,44 \%$ da área total. A aplicação da metodologia de determinação do relevo através Topographic Position Index apresentou um resultado que responde bem as feições de relevo observadas em campo, o que o potencializa para a aplicação em outras áreas.

Palavras-chaves: Índice de Posição Topográfico. Arroio Puitã. Relevo. Oeste do Rio Grande do Sul

\begin{abstract}
This study aimed to determine the Topographic Position Index (TPI) classes in the Arroio Puitã watershed. The Arroio Puitã is located in southern Brazil, western portion of the state of Rio Grande do Sul. The altimetric basis for defining the Topographic Position Index, were the radar data from the "Shuttle Radar Topography Mission" (SRTM). The TPI is the basis of the classification system, and is defined as the difference between a cell elevation value and the average elevation of the neighborhood around that cell. Positive values mean that the cell is higher than its surroundings, while negative values mean that it is lower. The scale used to define classes of TPI was 10 pixels, that is, we used a radius of 10 pixels for the neighborhood analysis composing the average altitude and sets the TPI value of the central pixel. TPI classes were socalled: Valleys, Lower Slopes, Gentle Slopes, Steep Slopes, Upper Slopes and Ridges. The area of Gentle Slopes predominates in the watershed with $38.06 \%$ of the total area. The areas of Steep Slopes and Lower Slopes, are the second and third in larger areas with $27.15 \%$ and $27.11 \%$ respectively. The area of the Ridges occupies the smallest area with only $0.44 \%$ of the total area. The implementation of the methodology for determining the relief through the Topographic Position Index presented a result that responds well to the major relief features observed in the field, potentializing its application to other areas.
\end{abstract}

Keywords: Topographic Position Index. stream Puitã; relief; West of Rio Grande do Sul. 


\section{INTRODUÇÃO}

O planejamento do uso e ocupação de uma determinada área deve basear-se não apenas na aplicação do conceito de aptidões e restrições da referida área, mas também em estudos que levem em consideração a importância ecológica e hidrológica de todos os componentes da paisagem (florestas, mata ciliar, banhados, etc.). A aplicação do Sistema de Informações Geográfico (SIG) combinado com o Modelo Digital de Elevação (MDE) possibilitam identificar, na paisagem, variáveis que descrevam processos hidrológicos, geomorfológicos e biológicos que são fundamentais para esse planejamento (MOORE et al., 1991).

A análise do relevo assume primordial importância, visto que condiciona o fluxo de materiais (água, nutrientes, sedimentos e contaminantes) e energia na paisagem (MOORE et al., 1991). Essas características controlam a variabilidade espacial da umidade do terreno (MOORE, 1988), das características dos solos, do processo erosivo e da degradação do solo e da água (MOORE e BURCH, 1986). Tais características podem ser avaliadas por um número significativo de índices topográficos que são úteis para identificar a susceptibilidade ao dano e que podem ser estimados usando técnicas de análise digital do terreno a partir do MDE.

Conforme Longley et al. (2005), as intensidades dos processos de dinâmica superficiais são sensíveis à posição topográfica, porém, existe grande dificuldade em se medir as variáveis para precisar sua descrição, devido a sua variabilidade espacial. A possibilidade de se obter de maneira simples índices topográficos que representem adequadamente essas variáveis complexas é um dos desafios atuais das modelagens ambientais.

O Índice de Posição Topográfico é uma ferramenta que possibilita a determinação de características da paisagem levando em consideração os atributos topográficos da área de estudo, desta forma, as unidades definidas apresentam uma estreita relação com condições de escoamentos hídrico e de dinâmica superficial.

Hoje, a grande maioria de estudos utiliza descritores qualitativos para analisar os componentes de paisagens. Assim, o geoprocessamento e as ferramentas de análise de dados de satélite são, cada vez mais, implementadas em estudos de paisagem.

Sistemas de informação geográfica (SIG) surgiram como uma forma eficaz de integrar e articular diferentes fontes de dados através da referência espacial (MAGUIRE e DANGERRAMOND, 1991). A capacidade analítica dos SIG pode ser utilizada de forma eficaz no campo da análise da paisagem (JOLIVEAU, 2003) e com destaque para os componentes da paisagem (CHÉTELAT, 2005). Além disso, o sensoriamento remoto é uma importante fonte que fornece informações sobre objetos através do levantamento e análise de dados sem contato direto entre o instrumento e o objeto analisado (BONN e ROCHON, 1992).

Assim sendo o presente trabalho tem como objetivo a determinação dos elementos do relevo da bacia hidrográfica do Puitã, usando como base na análise do Índice de Posição Topográfico.

A área da bacia hidrográfica do arroio Puitã abrange os municípios de Maçambará e São Borja,

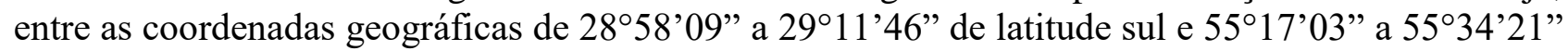
de longitude oeste como mostra a Figura 1.

\section{ÁREA DE ESTUDO}

A bacia hidrográfica do arroio Puitã, afluente da margem direita do rio Itú, compõem a bacia do rio Ibicuí, que é a maior bacia hidrográfica em território brasileiro, afluente do Rio Uruguai.

A referida bacia hidrográfica, apresenta uma área total de $392,53 \mathrm{~km}^{2}$ e perímetro de 95,80 $\mathrm{km}$. Possui uma amplitude altimétrica de $255 \mathrm{~m}$, com as nascentes em altitudes de $344 \mathrm{~m}$, até sua foz que está a 89 metros. O Padrão de Drenagem é retangular-dendrítico (CHRISTOFOLETTI, 1981), pois suas drenagens obedecem às linhas de falhas e fraturas geológicas que condicionam um forte controle estrutural da região. 


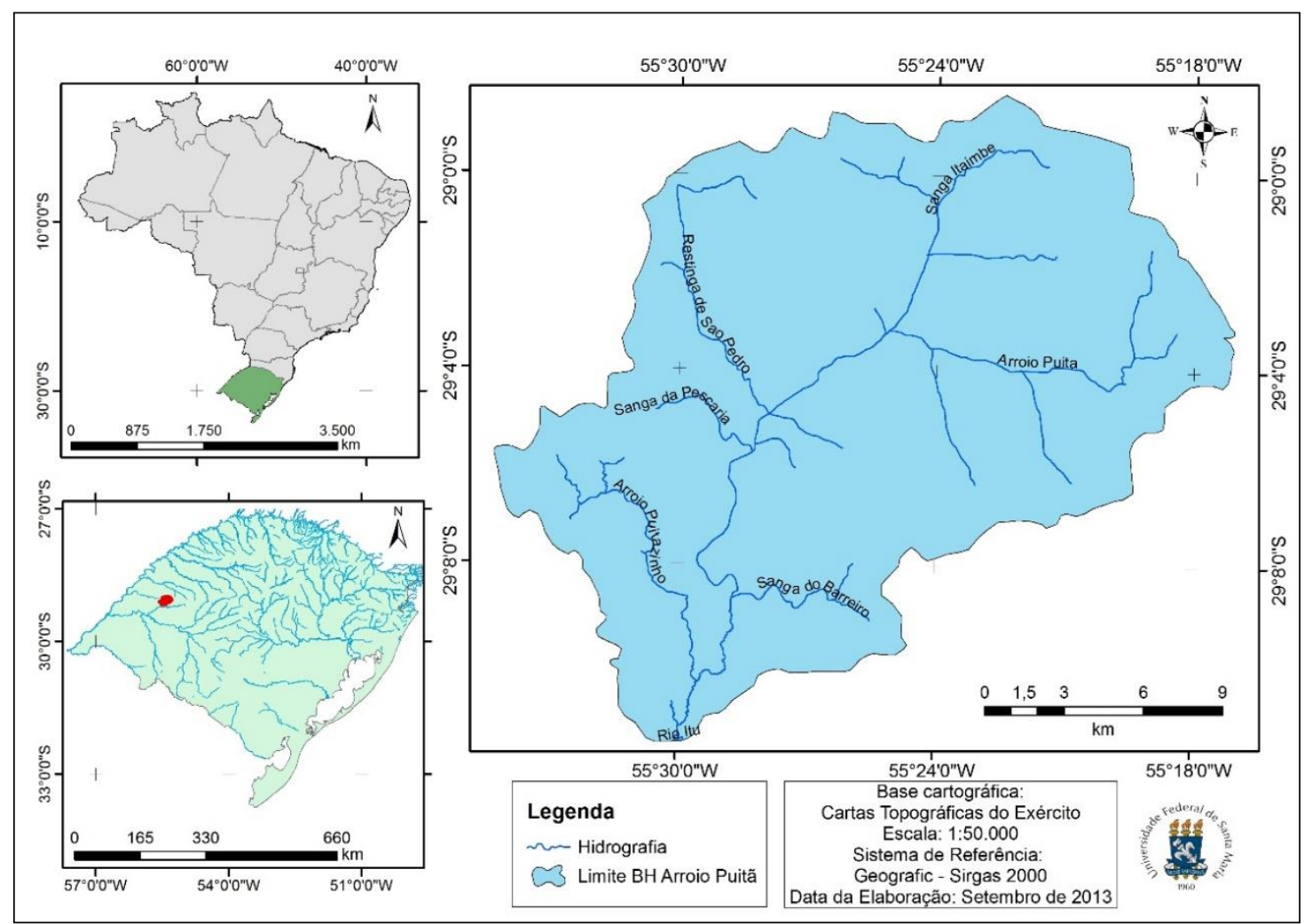

Figura 1: Localização da área de estudo. Org: os autores

As litologias encontradas na área são definidas como rochas vulcânicas e sedimentares, pertencentes à Bacia do Paraná e depósitos fluviais recentes. As rochas sedimentares, conforme Trentin (2011), é constituída de arenitos fluviais pertencentes à Formação Guará que se estende por toda a área e é um substrato muito friável, condicionando uma grande fragilidade frente aos processos de dinâmica superficial. Na porção do alto curso e junto aos divisores de água à sudeste, encontramse porções de arenito eólico da Formação Botucatu, associado à derrames vulcânicos da Formação Serra Geral.

Quanto aos solos predominantes na bacia hidrográfica Trentin (2011), apresenta que são solos encontrados sobre os substratos areníticos e, se caracterizam pela grande quantidade de quartzo em sua composição, geralmente com pouca presença de argilominerais e/ou outros ligantes do solo, por exemplo, a matéria orgânica.

Estes solos, comumente, são solos profundos associados às colinas de arenito, em que a alteração da rocha é maior e o solo desenvolve um perfil bastante espesso, porém ocorrem solos rasos associados aos topos dos morrotes, e às linhas de cornijas, em que os arenitos se encontram mais silicificado, apresentando alta resistência aos processos de intemperismo.

Conforme caracterização de Robaina et al. (2010), o arroio Puitã encontra-se inserido na unidade da Depressão do Ibicuí que constitui a porção oeste da Depressão Periférica do RS, com processos geomorfológicos controlados pela drenagem do Rio Ibicuí e seus afluentes, atuando sobre um substrato de rochas sedimentares de diferentes tipos, com predomínio de arenitos. Nessa unidade ocorrem amplas e alongadas formas de topos convexos, regionalmente, conhecidas como coxilhas onde os processos erosivos são significativos.

Ainda, conforme Robaina et al. (op. cit.), analisando o $3^{\circ}$ nível hierárquico de classificação geomorfológica, o Arroio Puitã encontra-se inserido no Modelado de Patamares Residuais em Arenitos que é constituída por formas de relevo do tipo colinas associadas à morrotes isolados de arenitos. As colinas formam um relevo ondulado, com inclinações inferiores a $15 \%$, associadas à morrotes com inclinações das vertentes superiores a 30\%. Os solos, predominantes, sobre as colinas são bem desenvolvidos e arenosos com pouca diferenciação entre os horizontes constituídos por Latossolos arenosos e, por vezes, devido ao baixo teor de argila, podem ser classificados como 
Neossolos. A presença de arenitos com baixa coesão e solos arenosos gera processos acelerados de erosão eólica e hídrica, formando feições como areais, ravinas e voçorocas.

\section{MATERIAIS E MÉTODOS}

A base cartográfica para o desenvolvimento do trabalho foi constituída das cartas topográficas desenvolvidas pela Diretoria de Serviços Geográfico do exército em escala 1:50.000, que permitiram a delimitação da bacia hidrográfica através dos cursos d'água, e configuração topográfica apresentada pelas curvas de nível e pontos cotados.

A base altimétrica para a definição do Índice de Posição Topográfico, foram os dados de radar do "Shuttle Radar Topography Mission", também conhecidos como SRTM, sendo estes dados utilizados para aplicação dos algoritmos propostos por JENNESS et al. (2013).

Conforme Jenness et al. (2013), o TPI é a base do sistema de classificação e, é simplesmente a diferença entre um valor de elevação de células e a altitude média da vizinhança em torno dessas células. Valores positivos significam que a célula é mais elevada do que os seus arredores, enquanto valores negativos significa que é mais baixa. Se ele é significativamente mais elevado do que a zona circundante, então é provável que seja no, ou perto do, topo de uma colina ou cume. Os valores significativamente baixos sugerem que a célula está no, ou, perto do fundo de um vale. O TPI com valores próximos de zero podem significar tanto uma área plana ou uma área de meados de inclinação, de modo que a inclinação da célula pode ser utilizada para distinguir os dois.

O índice de posição topográfica (TPI) compara a elevação de cada célula em uma altitude média do MDE, especificado em torno das células vizinhas (incluído em uma área cuja forma e extensão são determinados pelo usuário).

O valor expressa a intensidade do contraste, permitindo realçar as cristas ou os picos que são substancialmente mais elevados do que as suas células adjacentes. Significativamente valores inferiores de TPI sugerem que a célula está perto do fundo de um vale. O TPI com valores próximos de zero pode significar tanto um plano ou uma superfície de inclinação, a inclinação das células (declividade) pode então, ser utilizada para distinguir os dois (Figura 2).

O TPI é diretamente relacionado à escala de análise e conforme Jenness et al. (2013), o mesmo ponto na crista de uma montanha pode ser considerado um ridgetop para uma equipe de construção da estrada ou uma planície a um inseto que vive no solo.

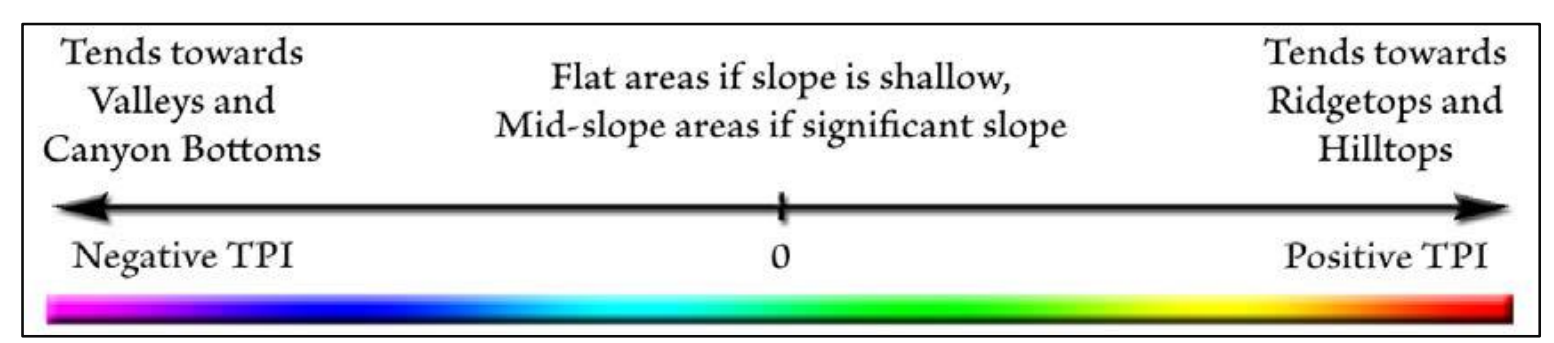

Figura 2: Distribuição dos valores dos pixeis do TPI em relação a diferença de altitude do pixel central em relação à média de seus vizinhos. Fonte: Jenness et al. (2013).

Por exemplo, na ilustração da Figura 3, o TPI é calculado para o mesmo ponto sobre a paisagem usando três escalas diferentes. Em cada caso, o ponto está localizado no topo de uma pequena colina, situada no interior de um vale maior. No caso A, a escala é grande o suficiente para que o ponto seja mais ou menos da mesma altura que a região de análise deste modo o valor TPI seria de aproximadamente 0 . No caso $\mathrm{B}$, a região de análise é grande o suficiente para abranger toda a pequena colina, e o ponto é, portanto, muito maior do que os seus vizinhos, apresentando assim um valor correspondente elevado para o TPI. No processo C, a escala inclui a colina e ambos os lados do vale, e, portanto, o ponto é mais baixo do que os seus vizinhos, apresentando um valor negativo para o TPI. 
Em ambiente SIG, a escala de análise pode ser traduzida pelo número de pixeis a qual realizase a janela de processamento das informações vizinhas.

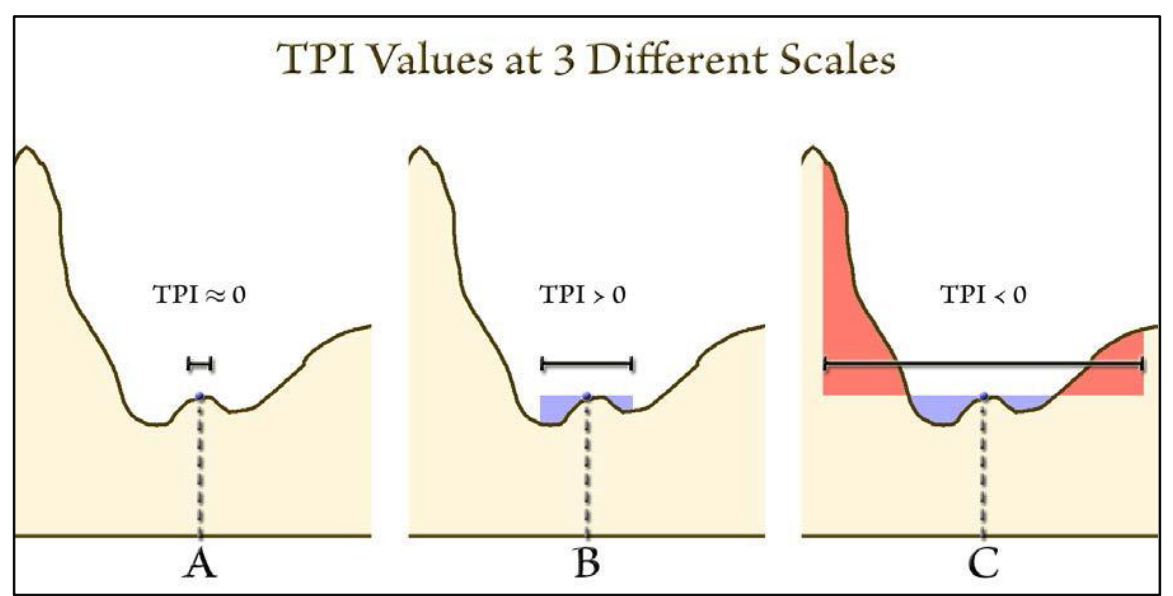

Figura 3: Modelo de definição do TPI utilizando diferentes escalas de análise. Fonte: Jenness et al. (2013).

Para definir as unidades do TPI, utilizou-se os dados SRTM, versão 2.1, que apresenta melhoramentos quanto a pixeis inconsistentes ${ }^{1}$, disponibilizados pela USGS (http://srtm.usgs.gov/), com resolução espacial de 90 metros. O método utilizado para delimitação dos TPIs, foi aplicado através das ferramentas (extensões) instaladas no ArcGIS 10.1, extensões estas disponibilizadas no site http://www.jennessent.com/arcgis/land_facets.htm. A escala utilizada para a definição das classes de TPI foi de 10 pixeis, ou seja, foi utilizado o raio de 10 pixeis para a análise da vizinhança e compor a média de altitude e estabelecer o valor de TPI do pixel central.

$\mathrm{Na}$ identificação das unidades de TPI da bacia hidrográfica do arroio Puitã foi utilizada as informações de elevação, bem como as inclinações das vertentes (declividade), para definição das seis unidades propostas. As seis unidades propostas pelo algoritmo são nomeadas Valleys, Lower Slopes, Gentle Slopes, Steep Slopes, Upper Slopes and Ridges, por padrão. A definição das classes segue os seguintes parâmetros:

Valleys (vales): $T P I \leq[\mathrm{A}]$

Lower Slopes (áreas planas): $[\mathrm{A}]<T P I \leq[\mathrm{B}]$

Gentle Slopes (encostas suaves): $[\mathrm{B}]<T P I \leq[\mathrm{C}]$, Slope Angle $<[\mathrm{S}]^{\circ}$

Steep Slopes (encostas ondulada): $[\mathrm{B}]<T P I \leq[\mathrm{C}]$, Slope Angle $\geq[\mathrm{S}]^{\circ}$

Upper Slopes (encostas íngreme): $[\mathrm{C}]<T P I \leq[\mathrm{D}]$

Ridges (topo das encosta): $T P I>[\mathrm{D}]$

Onde [A], [B], [C] e [D] são os valores dos limiares do TPI e [S] é o limiar do ângulo de inclinação (em graus).

Tendo em vista que os valores de TPI gerados para a bacia hidrográfica do Arroio Puitã apresentam uma variação de $-52,12$ à 67,48 , foram definidos os limiares de: $[A]=-16,[B]=-5,[C]=$ 16 e $[\mathrm{D}]=35$ para os valores de TPI (Figura 4) e, $[\mathrm{S}]=2,86$ como limiar do ângulo de inclinação. Estes valores representam a distribuição espacial das áreas em relação ao histograma de frequência. Quanto o limiar da inclinação o valor de $2,86^{\circ}$ corresponde a $5 \%$ de declividade. Este valor corresponde ao início dos processos erosivos e é proposto pelo IPT (1981), na definição de unidades

\footnotetext{
${ }^{1}$ Pixeis inconsistentes, referem-se aos pixeis que não apresentam valores de altitude coerentes, fruto de problemas de coleta dos dados, como massas de água e zonas costeiras gerando no modelo picos e poços.
} 
de relevo, bem como, é também utilizado por Robaina et al. (2014), na definição de unidades geomorfométricas na bacia hidrográfica do Ibicuí, no oeste do Rio Grande do Sul.

Conforme a distribuição das classes pré-definidas, estas foram renomeadas, usando a ferramenta "Redefinir Classe Nomes", levando-se em consideração a configuração que regionalmente são conhecidas, como: Valleys = Vales; Lower Slopes =Áreas planas; Gentle Slopes = Encostas suaves; Steep Slopes $=$ Encostas onduladas; Upper Slopes $=$ Encostas íngremes e Ridges $=$ Topo das encostas.

A escolha dos limiares, bem como a definição dos nomes das classes, foi baseada em conhecimento de campo da área de estudo.

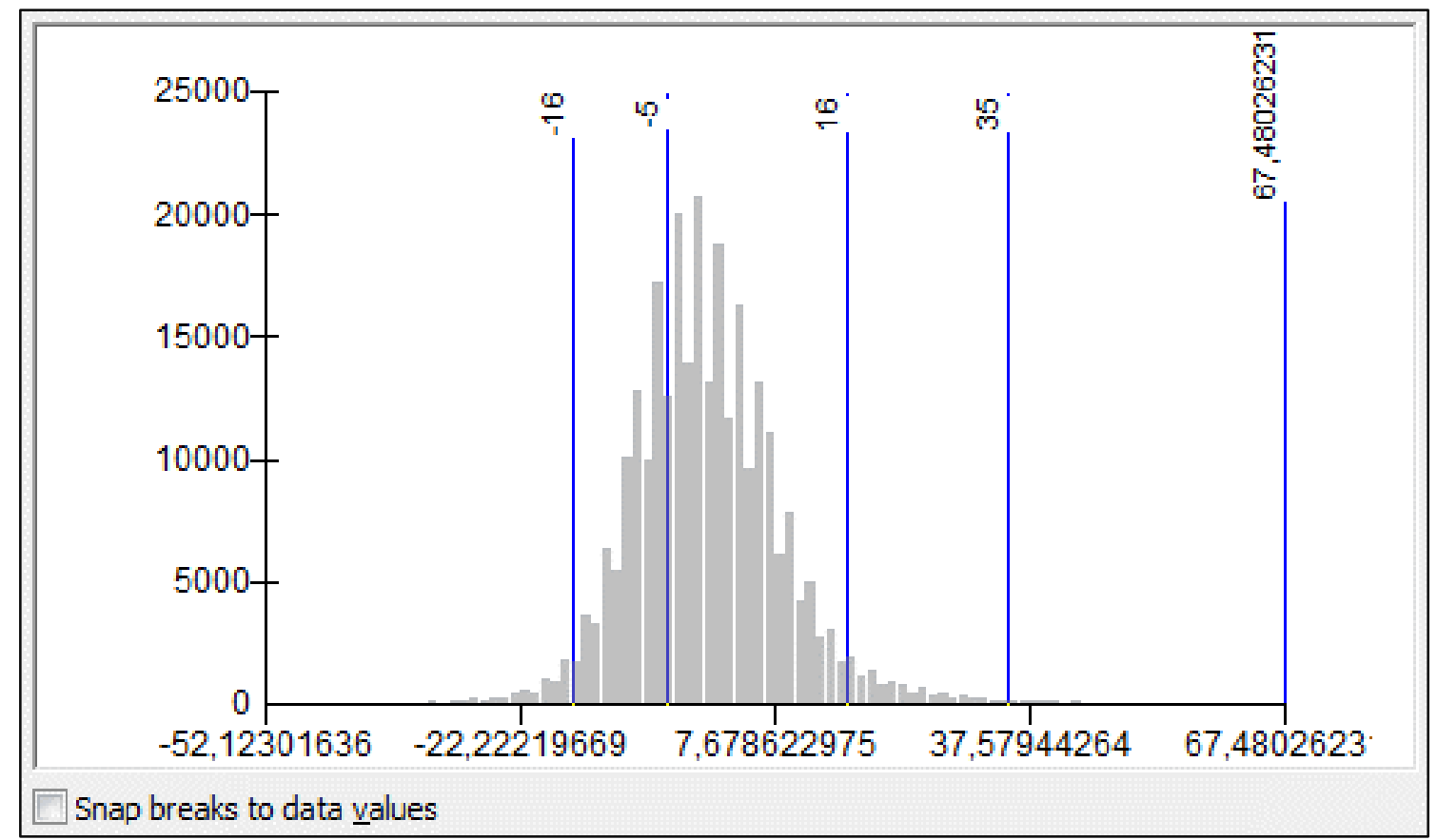

Figura 4: Histograma de frequência do TPI, com os limiares aplicados para delimitação das classes na bacia hidrografia do arroio Puitã. Org. Os autores

\section{RESULTADOS}

\section{Determinação do Índice de Posição Topográfico}

A Figura 5 apresenta a distribuição espacial geral do TPI, sendo considerando apenas a variação média de altitude dos pixeis vizinhos, em relação ao pixel central. Este índice apresentou a variação geral para a bacia hidrográfica do arroio Puitã de -52,12 à 67,95.

A bacia hidrográfica do Puitã caracterizada através do TPI apresenta 6 classes definidas como: Vales, Áreas Planas, Encostas suaves, Encostas onduladas, Encostas íngremes e Topo das encostas (Figura 6).

A Tabela 1 apresenta a distribuição da área e porcentagem das classes de TPI encontradas na bacia hidrográfica.

A classe de vales ocupa cerca de $12,85 \mathrm{~km}^{2}$ de área, que representa $3,27 \%$ da área total da bacia hidrográfica. Espacialmente localiza-se nas porções do alto curso da bacia, relacionada com as áreas onde o curso d'água aprofunda seu canal estabelecendo vertentes escarpadas. Apesar da classe não utilizar a inclinação das vertentes para definir a unidade, apenas os valores de TPI, em função de se utilizar o limiar de maior variação dos valores de TPI positivos, estas áreas estão associadas as porções encaixadas da drenagem que na bacia hidrográfica, por vezes formam pequenas quedas de água, como pode ser observado na Figura 7. 


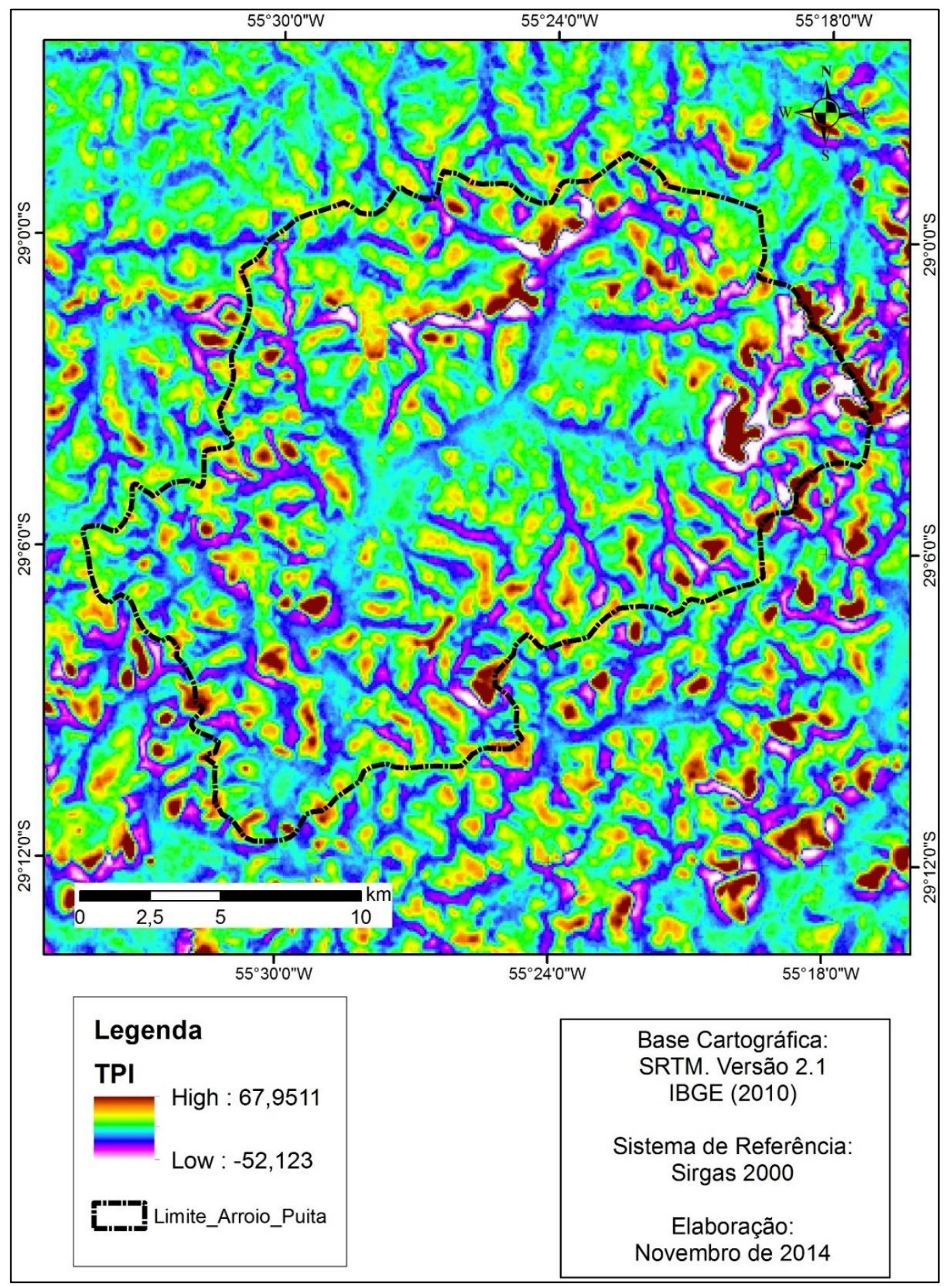

Figura 5: Distribuição geral do TPI na bacia hidrográfica do arroio Puitã. Org. Os autores

Tabela 1: Distribuição da área e porcentagem das classes de TPI

\begin{tabular}{l|c|c}
\hline \multicolumn{1}{c|}{ Classe } & Área_km ${ }^{2}$ & Porcentagem \\
\hline Vales & 12,85 & 3,27 \\
\hline Áreas planas & 106,42 & 27,11 \\
\hline Encostas suaves & 149,40 & 38,06 \\
\hline Encostas onduladas & 106,56 & 27,15 \\
\hline Encostas íngremes & 15,56 & 3,96 \\
\hline Topo das encostas & 1,73 & 0,44 \\
\hline
\end{tabular}




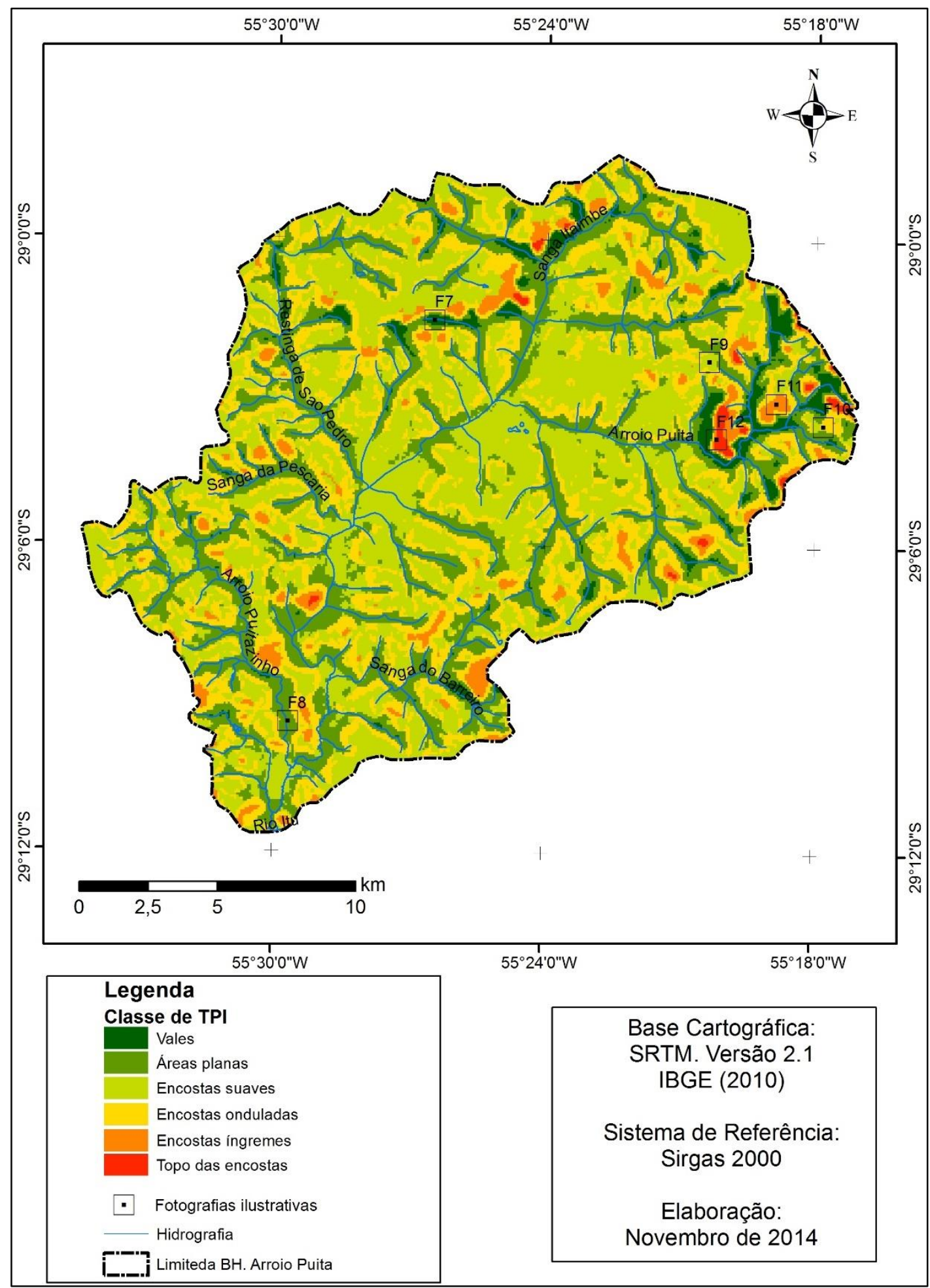

Figura 6: Mapa das classes de TPI na bacia hidrográfica do arroio Puitã. Org. Os autores 


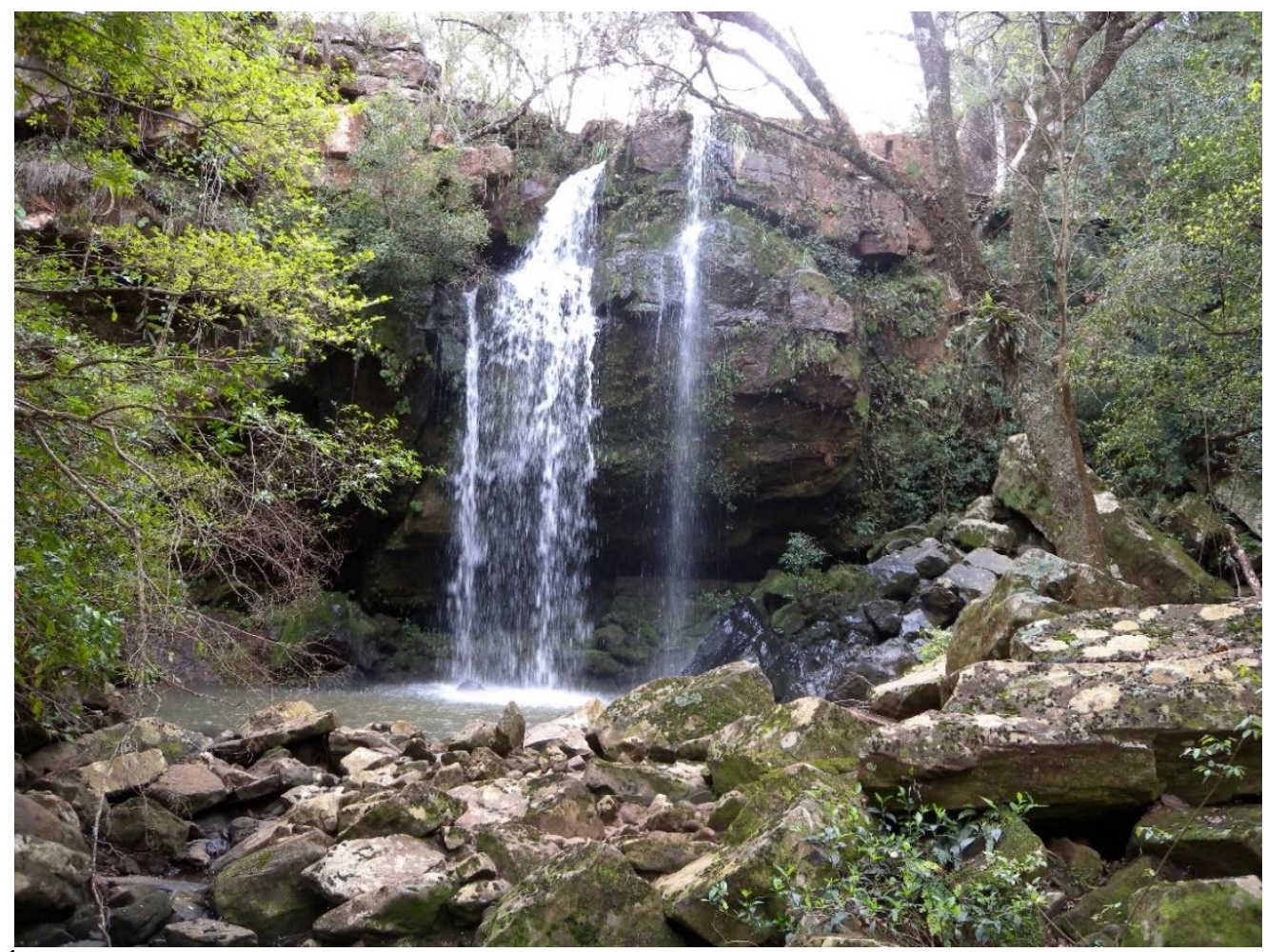

Figura 7: Áreas de vales, com formação de cachoeira. Foto dos autores, outubro de 2010.

A classe de Áreas planas ocupa uma área de $106,42 \mathrm{~km}^{2}$, que representa $27,11 \%$ da área total da bacia hidrográfica. Espacialmente esta classe encontra-se junto aos cursos de água, conforme configuração metodológica da definição das classes. Correspondem às porções do terço inferior da encosta e foram identificadas como correspondendo às planícies de inundações. A Figura 8 mostra áreas de planície de inundação.

A classe de encostas suaves representa a maior classe da bacia hidrográfica, com $149,40 \mathrm{~km}^{2}$, correspondendo à 38,06\% do total. Espacialmente encontra-se distribuída por toda a bacia hidrográfica. Esta classe caracteriza-se por baixas declividades, correspondendo a um relevo de colinas suaves, regionalmente conhecido como coxilhas. A Figura 9 mostra a as áreas de colinas presentes da bacia hidrográfica.

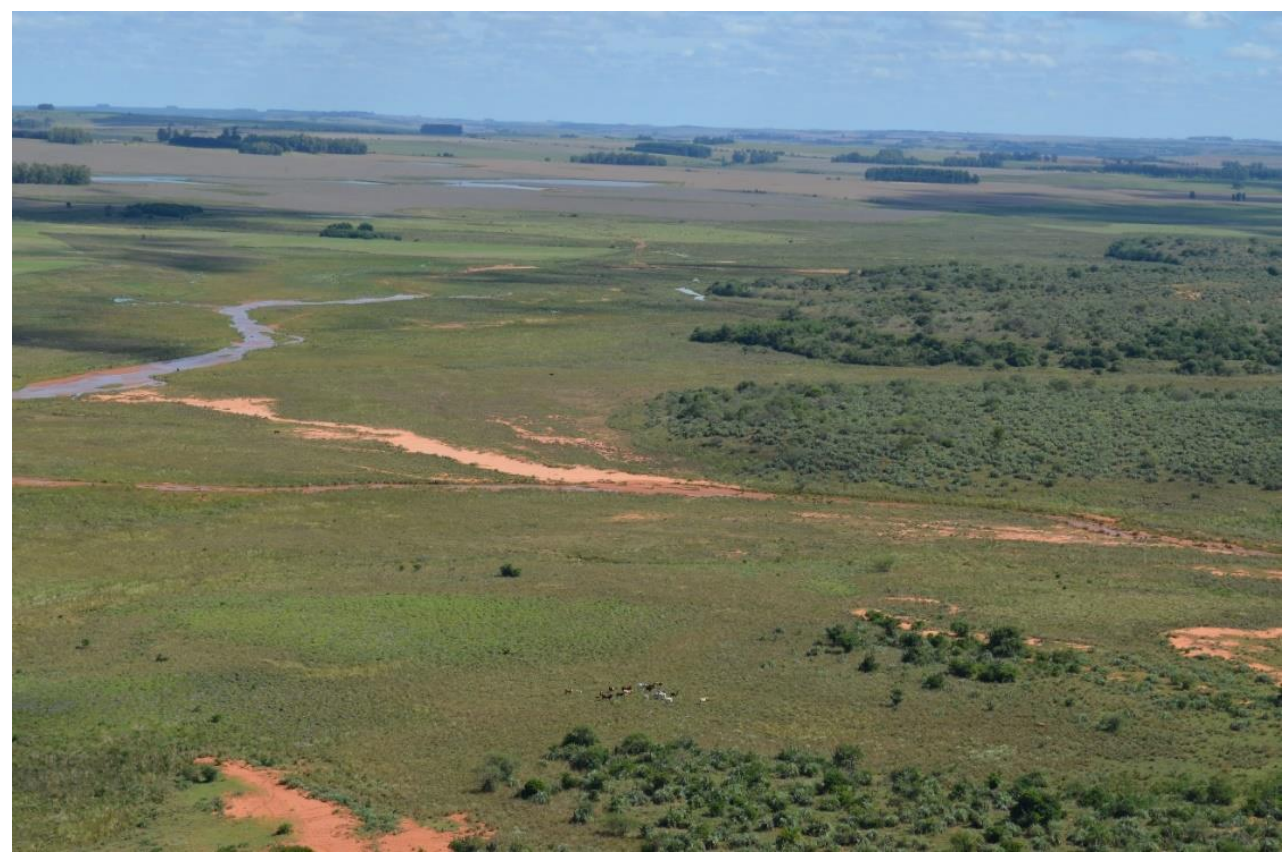

Figura 8: Planície de inundação de bacia hidrográfica do Arroio Puitã. Foto dos autores, abril de 2014 


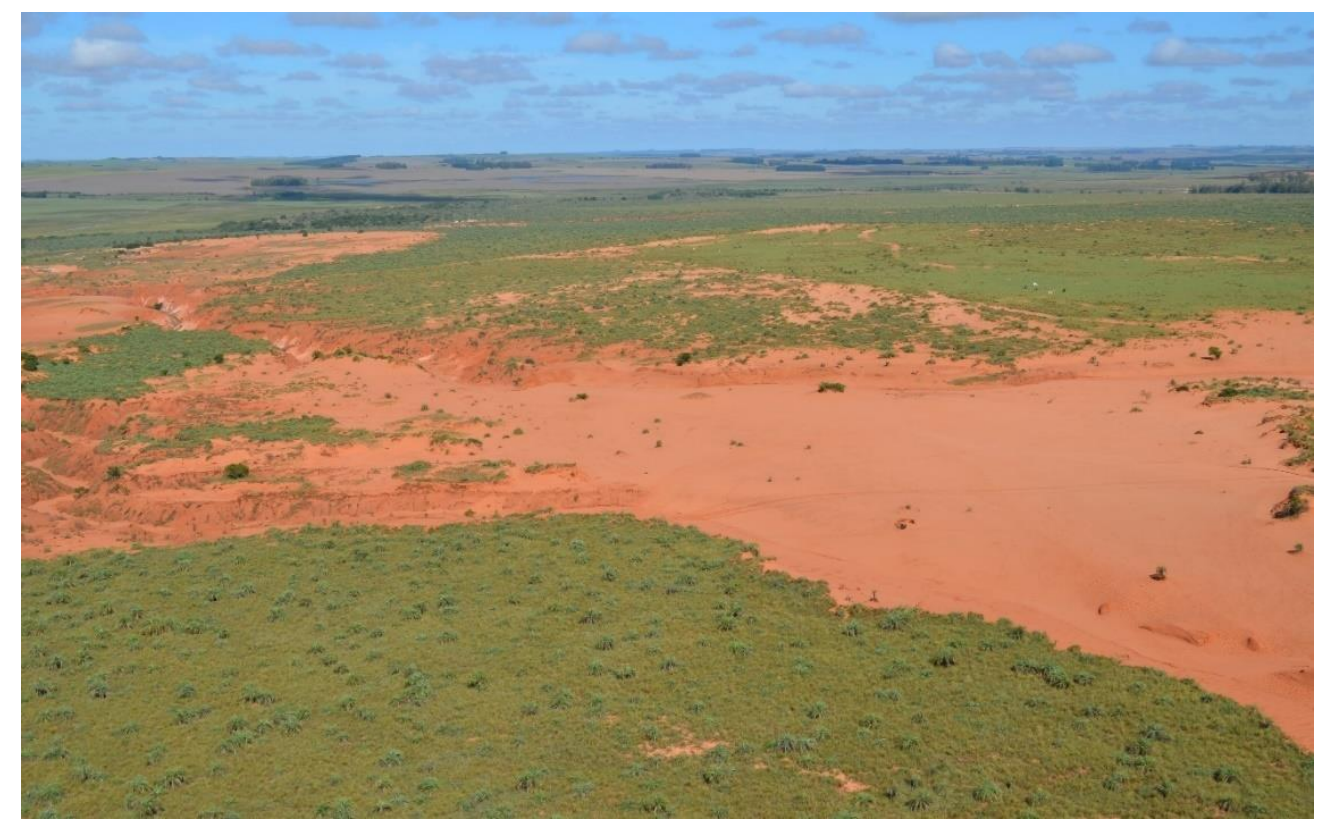

Figura 9: Colinas levemente onduladas do Arroio Puitã. Foto dos autores, abril de 2014

A classe das encostas onduladas forma uma porção de base do relevo de colinas junto a as áreas planas das planícies de inundação. Ocupa uma área de 106,56 km², o que representa 27,15\% da área total e corresponde a segunda maior classe em extensão espacial. Nestas porções os processos erosivos podem ser significativos, como é o caso apresentado na Figura 10.

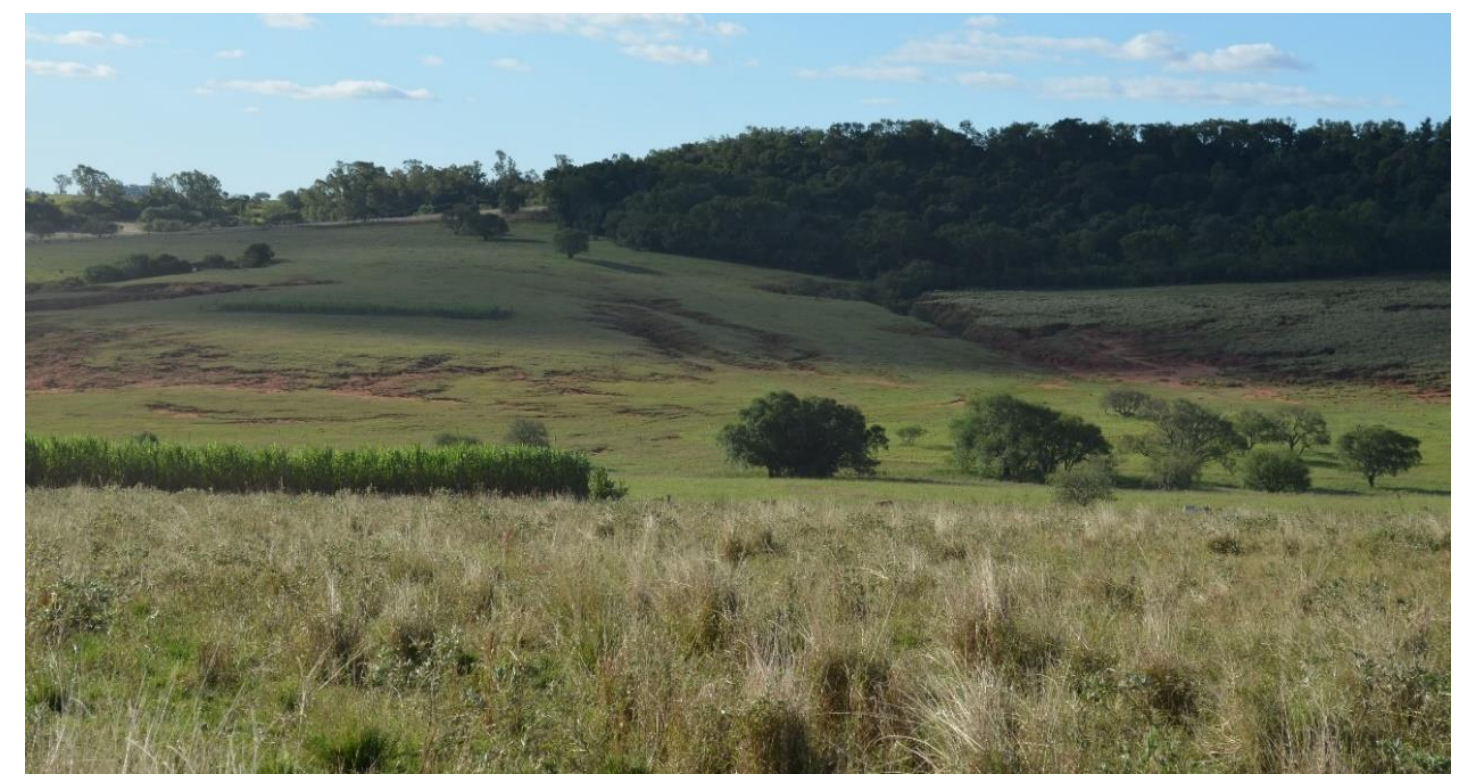

Figura 10: Colina na bacia hidrográfica do Arroio Puitã. Foto dos autores, abril de 2014

A classe das encostas íngremes corresponde a $15,56 \mathrm{~km}^{2}$, representando apenas 3,96\% da área total. Espacialmente esta classe encontra-se concentrada no alto curso da bacia hidrográfica, porém ocorrem em algumas porções isoladas ao longo da bacia. Esta classe é definida como estando associada a relevo de morros e morrotes. Espacialmente em campo, observa-se que estas áreas correspondem as porções mais elevadas, na maioria das vezes associadas ás porções de relevo de topos planos. A Figura 11 mostra duas situações desta classe em colinas de altitude, associado a porção de topo plano. 

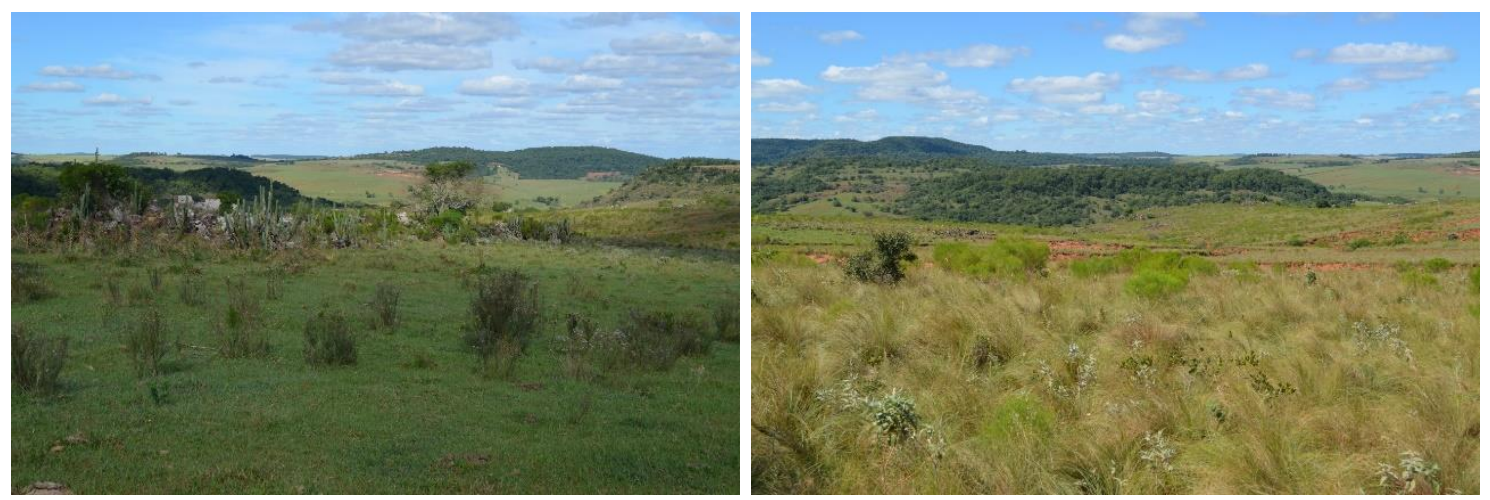

Figura 11: Colinas de altitude na bacia hidrográfica do Arroio Puitã. Foto dos autores, abril de 2014

A classe topo das encostas ocupa uma área de $1,73 \mathrm{~km}^{2}$ e representa $0,44 \%$ da área da bacia hidrográfica. Esta classe ocorre associada as encostas íngremes formando o topo dos morros e morrotes da área de estudo. A Figura 12 apresenta duas situações onde ocorre a classe topo de morros, sendo no primeiro caso, os topos de morrotes arredondados e no segundo os topos planos.
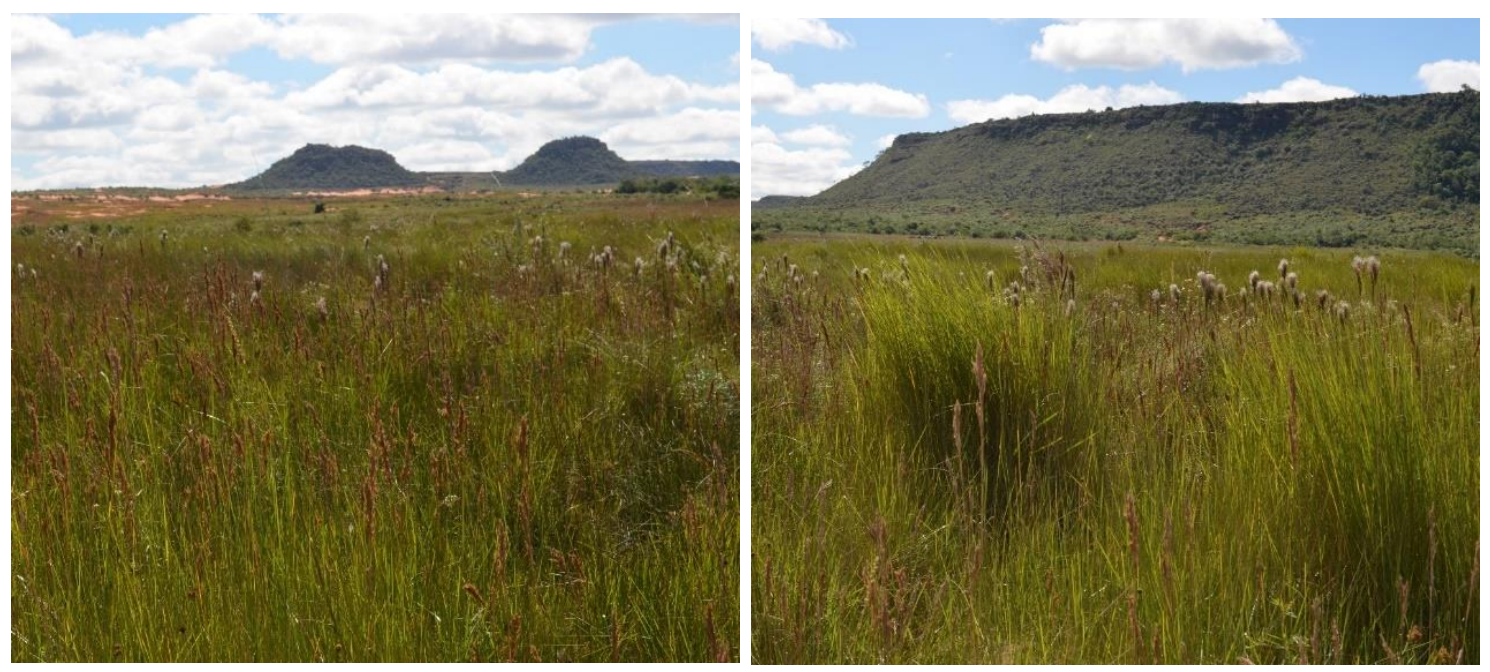

Figura 12: Morros e morrotes onde a classe de topo de morros ocorre na bacia hidrográfica do Arroio Puitã. Foto dos autores, abril de 2014

\section{CONSIDERAÇÕES FINAIS}

O desenvolvimento de estudos relevo tem grande importância para o estudo de bacias hidrográficas, pois fornecem situações concretas de interpretações. Este trabalho buscou estabelecer a aplicação metodológica de definição do Índice de Posição Topográfico da bacia hidrográfica do Arroio Puitã estabelecendo classes homogêneas, a fim de se estabelecer uma base para o desenvolvimento de trabalhos de relevo que possam subsidiar a realização de outros trabalhos, bem como ações de planejamento por parte dos órgãos responsáveis.

A bacia hidrográfica do arroio Puitã apresenta uma grande diversidade do relevo, desta forma, com a aplicação metodológica proposta e com um bom conhecimento de campo foi possível definir as seis classes de TPI, sendo denominadas conforme características regionais, assim definidas: vales, áreas planas, encostas suaves, encostas onduladas, encostas íngremes e topo das encostas.

As classes de encostas suaves, encostas onduladas e áreas planas predominam na bacia hidrográfica. A classe de encostas suaves, a mais abundante, tem cerca de $38 \%$ da área total, enquanto, a classe topo das encostas é a menos representativa, com apenas $0,44 \%$ da área total.

A aplicação da metodologia de definição do Índice de Posição Topográfico apresentou um resultado que responde bem as feições de relevo observadas em campo, o que o potencializa para a aplicação em outras áreas. O que se observa é a necessidade de um conhecimento prévio da área de 
estudo a fim que possam ser definida a escala de análise, bem como os limiares do TPI e da declividade, para a definição das classes do TPI.

\section{AGRADECIMENTOS:}

Os autores agradecem o apoio das agências de fomento CNPq, FAPERGS e Capes.

\section{REFERÊNCIAS BIBLIOGRÁFICAS}

BONN, F e ROCHON, G. Précis de télédétection: Principes et méthodes. Presses de l'Université du Québec.Sillery, 1992. vol. 1, p. 485.

BURROUGH, P. A. MCDONNELL R. A. Principles of Geographic Information Systems. Oxford, Oxford University Press, 1998.

CHÉTELAT, J. Eléments méthodologiques de diagnostic paysager utilisant les systems d'information géographique. Thèse de doctorat, Ecole polytechnique fédérale de Lausanne, 2005. p. 302.

CHRISTOFOLETTI, A. Geomorfologia fluvial: o canal fluvial. 2 ed. São Paulo: Edgard Blücher, 1981.

INSTITUTO DE PESQUISAS TECNOLÓGICAS. IPT. Mapeamento Geomorfológico do Estado de São Paulo. São Paulo. Escala 1:500.000, v. 2, 1981. 130 p.

JENNESS, J.; BROST, B.; BEIER, P. Land Facet Corridor Designer. USDA Forest Service Rocky Mountain Research Station, 2013

JOLIVEAU, T. Analyse des paysages dans un contexte d'aménagement. L'intérêt des outils géomatiques, Géoévénement. 2003.

LONGLEY, P.A.; GOODCHILD, M.; MAGUIRE, D.J.; RHIND, D.W. Geographic information systems and science. 2.ed. Chichester: Wiley, 2005. 497p.

MAGUIRE, D. e DANGERRAMOND, J. The Functionality of GIS. In: Maguire, D.; Goodchild, M.; Rhind, D. (eds) Geographical Information Systems: Principles and Applications. New York, John Wiley and Sons, 1991, pp. 319-35.

MOORE, I. D. e BURCH, G.J. Modeling erosion and deposition: topographic effects. Transactions of the ASAE, v.29, n.6, p.1624-1630, 1986.

MOORE, I.D., BURCH, G.J., MACKENZIE, D.H. Topographic effects on the distribution of surface soil water and the location of ephemeral gullies. Transactions of the ASAE, v.31, p.1098-1107, 1988.

MOORE, I.D., GRAUSON, R.B., LADSON, A.R. Digital terrain modeling: a review of hydrological, geomorphological and biological applications. Hydrological processes, v.5, p.3-30, 1991.

ROBAINA, L. E. S.; TRENTIN, R.; LAURENT, F.; CORBONNOIS, J. Classificação automatizada do relevo na bacia hidrográfica do Ibicuí, com parâmetros geomorfométricos hierarquizados por meio de uma árvore de decisão. In: Envibras2014: Environnement et géomatique: approches comparées France - Brésil. Anais... 2014

ROBAINA, L.E.S.; TRENTIN, R.; BAZZAN, T.; RECKZIEGEL, E.W.; VERDUM, R.; DE NARDIN, D. Compartimentação geomorfológica da bacia hidrográfica do Ibicuí, Rio Grande do Sul, Brasil: proposta de classificação. Revista Brasileira de Geomorfologia, v.11, n.2, p.11-23, 2010

TRENTIN, R. Mapeamento geomorfológico e caracterização Geoambiental da Bacia Hidrográfica do Rio Itu - Oeste do Rio Grande do Sul - Brasil. Curitiba. UFPR. 2011. Tese de doutorado. 